\title{
Comparing kernel damage of different threshing components using high-speed cameras
}

\author{
Zheng $\mathrm{Ma}^{1}$, Min $\mathrm{Han}^{1}$, Yaoming $\mathrm{Li}^{1^{*}}$, Shuncheng $\mathrm{Yu}^{1}$, Farman Ali Chandio ${ }^{2}$ \\ (1. Key Laboratory of Modern Agricultural Equipment and Technology, Ministry of Education; High-tech Key Laboratory of \\ Agricultural Equipment and Intelligence of Jiangsu Province; School of Agricultural Equipment and Engineering, \\ Jiangsu University, Zhenjiang 212013, Jiangsu, China; \\ 2. Sindh Agriculture University, Faculty of Agricultural Engineering, Tandojam, Sindh, Pakistan)
}

\begin{abstract}
Grain damage research has been a focus of many experts in the agriculture machinery industry. A threshing test-bed was developed to investigate the movement and influence of different threshing and separating units on maize grains. The damage to maize grains was analyzed with a high-speed camera to observe the movement and damage received by the maize grains. The results showed that the threshing and separating effects of the perforated concave plate were obviously lower than that of the round steel concave plate, the threshing effects of the rigid rasp bar and polyurethane rasp bar were similar, and the damage ratio of the polyurethane rasp bar was relatively low. It also indicated that moisture content has a significant effect on the damage ratio and damage type of maize grains. The different threshing component types used in this study had an obvious effect on the degree of damage to high moisture content maize grains and the damage to high-moisture kernels during threshing could be further identified. The results can provide a reference for the design of threshing and separating devices in the maize combine harvesting machinery.
\end{abstract}

Keywords: maize grain, damage, threshing process, high-speed camera

DOI: $10.25165 /$ j.ijabe.20201306.5395

Citation: Ma Z, Han M, Li Y M, Yu S C, Chandio F A. Comparing kernel damage of different threshing components using high-speed cameras. Int J Agric \& Biol Eng, 2020; 13(6): 215-219.

\section{Introduction}

The yield and planting area of maize is the largest among the three main grain crops (maize, rice, and wheat) in China. However, the mechanization ratio of maize is the lowest among them (maize-69\%, rice- $87 \%$, wheat- $95 \%^{[1]}$ ). Currently, the demand for mechanization of maize harvesting is becoming increasingly urgent. Maize combine harvesters enjoy higher market popularity because of their advantages in reducing operation procedures and saving labor and time ${ }^{[2]}$. In China, the maize grain of harvested maize has high moisture content in regions adopting the wheat-maize rotation cropping system. Relevant studies show that levels of moisture content have a significant effect on the characteristics of maize ${ }^{[5]}$. Maize grain with higher moisture content is prone to breaking during threshing. The high rate of kernel damage has become an important restricting factor in popularizing and applying maize grain combine harvest technology in China ${ }^{[7]-}$.

There are numerous studies on the damage to maize grains during the threshing process. Chowdhury et al. ${ }^{[11]}$ conducted an

\section{Received date: 2019-09-12 Accepted date: 2020-06-22}

Biographies: Zheng Ma, PhD, Associate Professor, research interests: design and research of modern agricultural machinery, Email: mazheng123@ujs.edu.cn; Min Han, Master, research interests: design and research of modern agricultural machinery, Email: 2642085984@qq.com; Shuncheng Yu, Master, research interests: design and research of modern agricultural machinery, Email: 1263266052@qq.com; Farman Ali Chandio, PhD, Associate Professor, research interests: design and research of modern agricultural machinery, Email: farman_chandio@hotmail.com.

*Corresponding author: Yaoming $\mathbf{L i}, \mathrm{PhD}$, Professor, research interests: design and research of modern agricultural machinery, Jiangsu University, School of Agricultural Equipment Engineering, Zhenjiang 212013, Jiangsu, China. Tel: +86-13805283656, Email: prof_lym@126.com. experimental study on grain damage caused by maize threshing and classified the damage to be severe including crown damage, pericarp damage, embryo damage, and sieved material. Pericarp damage accounted for majority of the losses. According to Kustermann et al. ${ }^{[12]}$, threshed kernels moved in multiple directions within the threshing device, resulting in the speed of threshed maize being four times slower than the other threshing components. Petkevichius et al. $^{[13]}$ analyzed the threshing, separation and damage of maize grain with different threshing clearances. $\mathrm{Li}$ et al. ${ }^{[14]}$ studied the movement of ears and kernels during the threshing process using high-speed camera technology. Zhang et al. ${ }^{[15]}$ analyzed the mechanical relationship between maize grain and different threshing components in the process of mutual contact and found that there were obvious differences in the mechanical action between maize grain with the nail tooth, the plate tooth and their different parts in the process of mutual collision.. Their results suggest that the larger the contact area, the stronger the striking action between maize grains and threshing components; the force of interaction can be reduced when the contact plate is flat.

There is no suitable maize combine harvesting machine currently available for commercialization in China. With in-depth studies, many different methods of analysis and simulations have been developed ${ }^{[16]}$ and various test-beds were gradually developed ${ }^{[19]}$. Research on the threshing of high moisture content maize (mainly through experimental methods) indirectly analyzes the mechanisms that damage maize. However, there is a lack of research on the interactions between maize grain and threshing components during threshing. Thus, a maize grain threshing test-bed based on the maize combine harvesting machine was developed in this study to investigate the effect of threshing components on maize grain and its movement during threshing. 
The threshing and separating processes of maize grains with different threshing and separating devices were recorded and analyzed via high-speed camera, and the damage to maize grain during the threshing process was statistically analyzed.

\section{Structure and methods}

\subsection{Structure}

The overall structure of the maize grain threshing test-bed was composed of a threshing cylinder, threshing component, separating concave plate, conveying and feeding device, transmission device, material collecting device, and frame (Figure 1).

The side baffles of the test-bed were acrylic transparent plates with good light transmission and a certain amount of strength and impact resistance. The YVF2-112M-4 horizontal variable frequency motor with a power of $4 \mathrm{~kW}$ and a rated speed of 1430 $\mathrm{r} / \mathrm{min}$ was selected to provide the power output for the test-bed, and a frequency converter was used to control the speed.

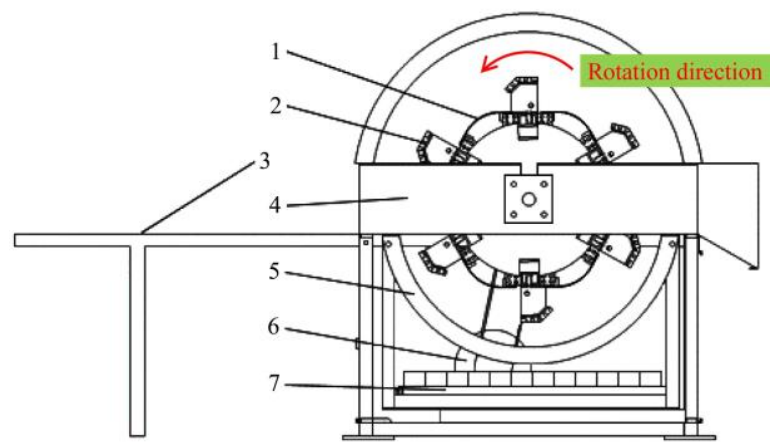

1. Threshing cylinder 2. Threshing component 3. Conveying and feeding device 4. Frame 5. Separation concave plate 6. Transmission device 7. Material collecting device

Figure 1 Structure diagram of maize grain threshing test-bed

\subsection{Design of main components}

The threshing cylinder and separating concave plate were the key components of the test-bed. In order to study the influence of various threshing component types during the threshing process, the threshing cylinder design allowed convenient replacement of threshing components.

The new designed threshing cylinder (Figure 2a) consists of a sealing plate, threshing component, ear plate, central shaft, C-shaped steel channel, and a web plate. The center of the web plate was fixed along the central shaft. Six notches were uniformly distributed along the circumferential direction of the web plate, and the C-shaped steel channel was assembled by placing them into the notches on the web plate through the ear plates. The sealing plate between the ear plates of two adjacent $\mathrm{C}$-shaped steel channels was connected using bolts to form a closed roller. The threshing component with the $\mathrm{C}$-shaped channel steel through the base was assembled and fixed, which allowed quick replacement of different threshing component types. The structure of the separating concave plate (Figure 2b) consisted of round steel, ribbed plates, side plates, and a bracket. The concave plate was installed on the bracket using bolts, so that different types of concave plates could be replaced from the side of the threshing device.

The concave plate bracket was fixed to the frame using a threshing clearance adjustment structure (Figure 3). The threshing clearance adjustment structure mainly consisted of a concave plate bracket, threaded rod, fixing nut, backing plate, and frame. The concave plate bracket was fixed to the frame of the test-bed with a threaded rod. The upper, lower, left, and right positions of the whole structure of the concave plate bracket were adjusted through the backing plate and long slotted holes on the concave plate bracket, accomplishing threshing clearance adjustment.

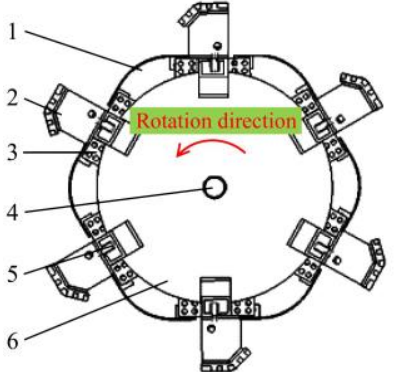

a. Threshing cylinder

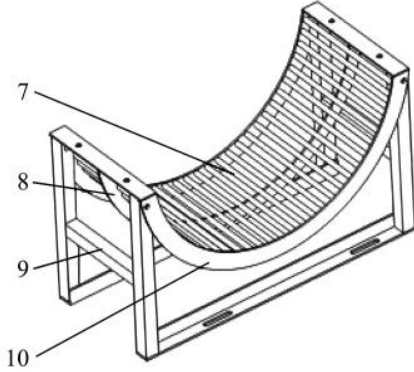

b. Separating concave plate
1. Sealing plate 2. Threshing component 3. Ear plate 4. Central shaft 5. C-shaped steel channel 6. Web plate 7. Round steel 8. Ribbed plate 9. Bracket 10. Side plate

Figure 2 Structural diagram of threshing component

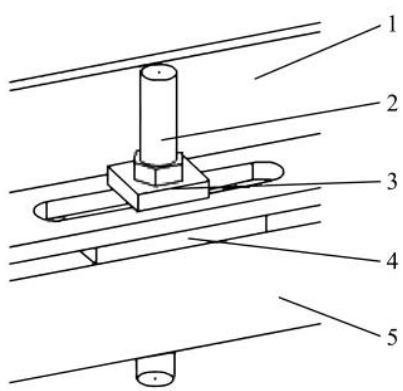

1. Concave plate bracket 2. Threaded rod 3. Fixing nut 4. Backing plate 5. Frame

Figure 3 Structure diagram of threshing clearance adjustment structure

\subsection{Working process}

The maize ears were fed into the test-bed through a conveying and feeding device and used a belt alongside the frequency conversion motor to drive the rotation of the threshing cylinder. The threshing component rotated along with the threshing cylinder. The maize ears then entered the clearance of the concave plate where threshing was carried out through squeezing, rubbing, and striking of the threshing component, the separating concave plate, and top cover. The threshing process of the maize grain was observed and recorded by the high-speed camera system from the side of the test-bed. The threshed maize grain and the broken maize ear were separated, and fell into the lower material collecting device through the separating concave plate.

\section{Test methods}

The maize threshing process was recorded by a i-SPEED3 high-speed camera system without any additional monitor or computer to change the settings, record, and playback. The editing and playback options were utilized to quickly confirm and save relevant image data.

The high-speed camera system (Figure 4) was placed adjacent to the maize threshing test-bed. The position, manual focus and lens aperture of the high-speed camera systems were adjusted, and the sampling speed was set to 300 frames/s with a resolution of $1280 \times 1024$.

Two types of separating concave plates were used in the test: a round steel concave plate and a perforated concave plate (Figure 5a.). The round steel concave plate could provide more threshing intensity and made rod-like materials more easily be separated than 
the perforated concave plate, while the later one could make more whole grains be separated.

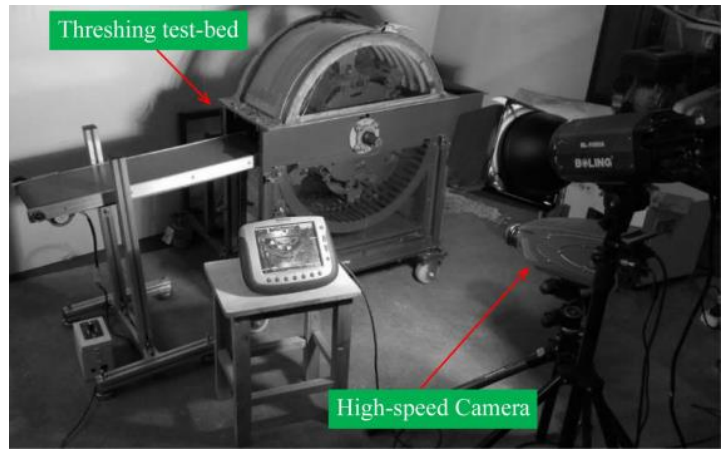

Figure 4 Threshing test scene of high-speed camera

There were four types of threshing components: rigid nail tooth, rigid tooth plate, rigid rasp bar, and polyurethane rasp bar (Figure 5b). As known that the rigid nail tooth could provide more hit and grab ability for the threshing cylinder, while the tooth plate could provide more promoted capacity to the materials. On the other hand, the rigid rasp bar could produce a relatively gentle threshing process than the previous 2 components, while the polyurethane rasp bar could reduce impact failure to maize grains.

The number of each threshing component varied with 15 rigid nail tooth components, 12 rigid tooth plate components, 6 rigid rasps bar components, and 6 polyurethane rasp bar components. The threshing components were distributed uniformly along the circumference of the threshing cylinder, and arranged six rows of threshing components in a double helix.

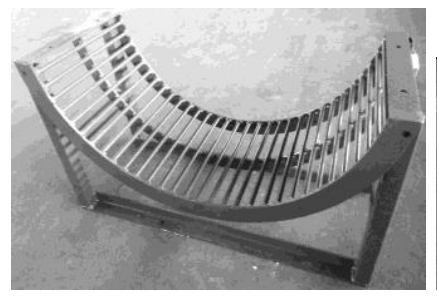

Round steel concave plate

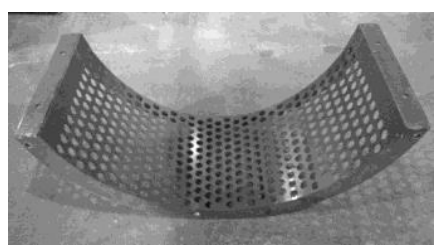

Perforated concave plate a. Separating concave plate

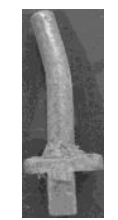

Rigid nail tooth

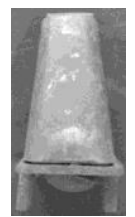

Rigid tooth plate

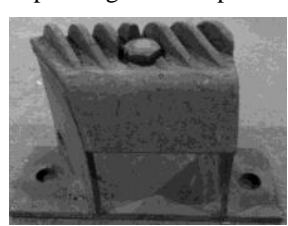

Rigid rasp bar

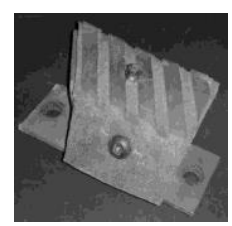

Polyurethane rasp bar

b. Threshing component

Figure 5 Different types of threshing and separating components

The uniform working parameters in the threshing process test were set for the purpose of comparative analyses and feasibility. The rotating speed of the drum was $350 \mathrm{r} / \mathrm{min}$, and the threshing clearance was $40 \mathrm{~mm}$. Different types of threshing components and separating concave plates were replaced based on this.

Two moisture content levels in maize grain $(32.1 \%$ and $25.6 \%)$ were selected, and the amount of damaged maize grain was analyzed produced by each threshing component.

Fully grown maize ears with complete kernels were used in the experiment, the maize bracts were removed manually; and the maize ears were fed into the test-bed in a position parallel to the axis of the threshing cylinder. Repeated experiments were conducted under different conditions.

\section{Results and analysis}

\subsection{Results and analysis of threshing process}

The threshing process of different threshing components was recorded with the high-speed camera system, and it was compared with observations to analyze the effects of different threshing components in the maize threshing process.

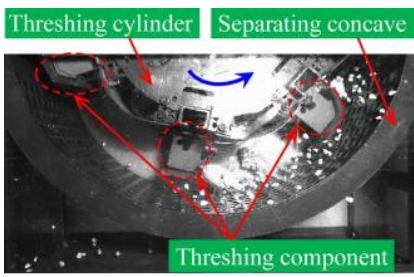

a. Perforated concave plate threshing moment

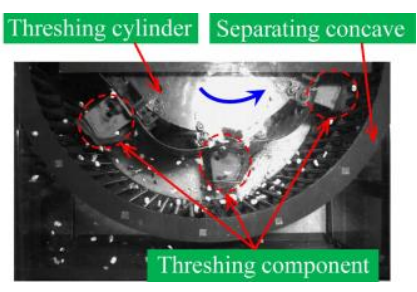

b. Round steel concave threshing moment
Figure 6 Threshing process of two concave plate types

The entire threshing process of the round and perforated steel concave plates were observed (Figure 6). The results indicated that most maize ears within the perforated concave plates passed through the threshing device in a relatively complete form. Small amounts of kernel were threshed under the impact of the threshing components, and the threshed kernels were not separated by the concave plates in time. The maize ears in the round steel concave plate had a faster threshing speed upon entering the threshing device; the threshed kernels moved in multiple directions, dispersed in a larger degree, and passed through the round steel concave plate in time. The results suggested that the performance of the round steel concave plate exceeded that of the perforated plate.

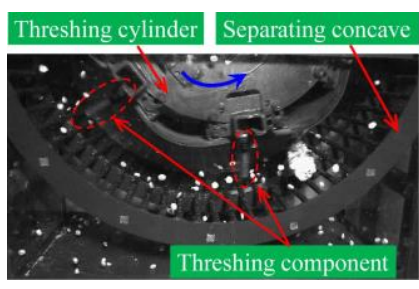

a. Rigid nail tooth threshing moment

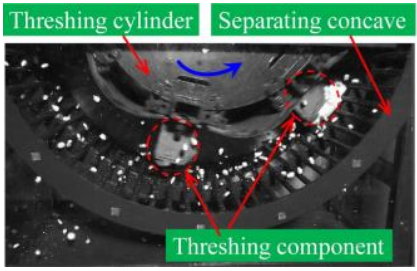

c. Rigid rasp bar threshing momen

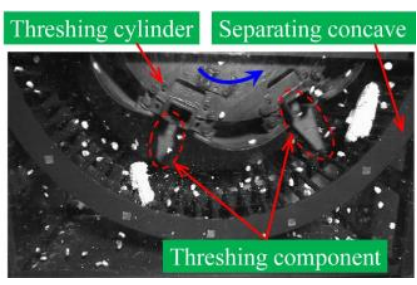

b. Rigid tooth plate threshing moment

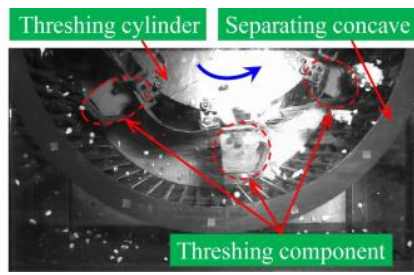

d. Polyurethane rasp bar threshing moment
Figure 7 Threshing process of different threshing components

The whole threshing process was observed and found that when the maize ears were threshed under the rigid nail tooth component, the maize ears were continuously turned over and their positions changed constantly under the continuous impact of the nail tooth, drum, and concave plate (Figure 7.). Threshed kernels mainly originate from the impact of the nail tooth components on the maize ear. In most cases, the maize ears passed through the threshing device in a relatively complete form resulting in inefficient threshing. When the impact was too large, the maize ear would break.

It is found that compared with the rigid nail tooth component, the maize ears easily broke under the impact of the rigid tooth plate 
component through observation. A portion of the broken maize ear continuously rotated under the impact of the tooth plate and concave plate. The maize grains were threshed naturally via rubbing of the tooth plate and maize ear. The other part was continuously impacted by the tooth plate, drum, and concave plate; further increasing the degree in which the maize ear was broken.

The threshing process of the rigid rasp bar component and polyurethane rasp bar component were similar by observation. The maize ears were threshed mainly under the rubbing impact of the rasp bar component and concave plate. The inclined section of the rasp bar component surface had a certain strike impact with the drum rotating continuously during the threshing process. It was noticed that the maize ears rotated along the inclined surface due to the interaction of the rasp bar component and concave plate after contact with the maize ears. Then the maize ear was squeezed from contact with the top surface of rasp bar component. It was witnessed that the maize ear was threshed while rotating under the squeezing and rubbing impact of the rasp bar.

\subsection{Results and analysis of damage maize grain}

The damaged kernels were divided into three categories (Figure 8): cracked kernels had visible cracks in the maize grains; defective kernels contained damage covering less than $1 / 3$ of the maize grains; broken kernels were completely broken into irregular shapes. Process the statistic data on the quality of threshed kernels, crack kernels, defect kernels and broken kernels.

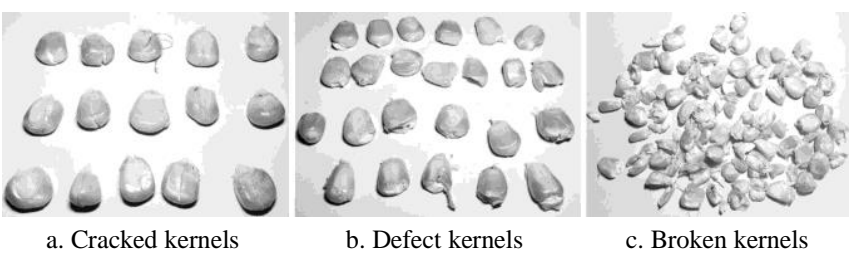

Figure 8 Different categories of maize grain damage

The threshing results of a single maize ear under different threshing components are shown in Table 1.

Table 1 Results of maize threshing damage

\begin{tabular}{|c|c|c|c|c|c|c|c|}
\hline Threshing components & Moisture content & Threshed kernels/g & Crack kernels/g & Defect kernels/g & Broken kernels/g & Total damage kernel/g & Total damage rate $/ \%$ \\
\hline \multirow{2}{*}{ Nail tooth } & $32.1 \%$ & 133.93 & 2.40 & 3.35 & 4.57 & 10.31 & 7.7 \\
\hline & $25.6 \%$ & 149.17 & 0.51 & 0.75 & 1.55 & 2.81 & 1.88 \\
\hline 10041 prate & $25.6 \%$ & 141.73 & 0.52 & 0.79 & 1.49 & 2.80 & 1.98 \\
\hline \multirow{2}{*}{ Rigid rasp bar } & $32.1 \%$ & 142.53 & 2.04 & 1.56 & 4.14 & 7.73 & 5.42 \\
\hline & $25.6 \%$ & 138.52 & 0.29 & 0.55 & 1.20 & 2.04 & 1.48 \\
\hline Polyurethane rasp bar & $25.6 \%$ & 143.00 & 0.53 & 0.14 & 0.97 & 1.64 & 1.15 \\
\hline
\end{tabular}

According to the results of the statistical analysis, the proportion of damaged maize grains were significantly reduced at the $25.6 \%$ moisture content level compared to the $32.1 \%$ moisture content level. The strength of the stalk of maize grains was positively correlated with moisture content level combined with the relevant research on the threshing force of maize. An interactive force between maize grains increased the difficulty of threshing the kernels off the maize ear by observation. Therefore, it was determined that more force was required in the threshing process, and that damage will occur when the force exerted on maize grains is greater than the kernel durability. The results showed that moisture content significantly affected the rate of damaged kernels, and that there was a significant reduction in the total rate of damage received by maize grains at a $25.6 \%$ moisture content level.

The total damage rate of maize grains was taken as an evaluation index, and it was found that the threshing effect of the polyurethane rasp bar component was relatively good. The different threshing component types influenced the damage rate of maize grains with high moisture content levels were observed. And the results indicate the maximum difference of the total damage rate is $3.42 \%$. The nail tooth component reduced damage by $9.41 \%$ compared to the tooth plate component. The rigid rasp bar component reduced damage by $36.23 \%$ while the polyurethane rasp bar component reduced damage by $40.24 \%$. There was no obvious difference between the total damage rate of the rigid rasp bar and polyurethane rasp bar as observed. It was believed that the flexibility of the polyurethane rasp bar component limited the degree of impact on the maize grains; The flexibility in maize grains was improved caused by higher moisture content further reducing the force of impact in the polyurethane rasp bar component to some extent. The damage rate in different threshing component types was reduced when decreased moisture content. The results show that the maximum difference in the total damage rate is $0.83 \%$. Compared to the tooth plate component, the nail tooth component reduced damage by $5.05 \%$, the rigid rasp bar component reduced damage by $25.25 \%$. And the polyurethane rasp bar component reduced damage by $41.91 \%$. The difference between the total damage rate of the rigid rasp bar and polyurethane rasp bar increased as can be seen. This highlighted the effect of polyurethane component materials on maize grain threshing as more and more significant with decreased moisture content.

The proportion of broken kernels at the $25.6 \%$ moisture content level was significantly higher compared to the $32.1 \%$ moisture content level in Figure 9. The proportions increased as follows: $11 \%$ with the nail tooth, $7.4 \%$ with the tooth plate, $5.3 \%$ with the rigid rasp bar, and $21.5 \%$ with the polyurethane rasp bar.

According to the basic characteristics of maize grains; grain hardness was negatively correlated with moisture content resulting in brittleness that allows damage to occur easily during threshing. The flexibility of the grain is positively correlated with moisture and can be observed in grains that underwent elastic deformation. In this study there is a higher proportion of cracked and defective maize grains with a moisture content of $32.1 \%$, and broken maize grains with a moisture content $25.6 \%$ significantly increased under the impact force of threshing process.

There was no significant difference between the damage rate in the nail tooth and the tooth plate. During the threshing process of the maize ear with the nail tooth component; the contact area with the maize grain was small which concentrated the force; and the threshing was mainly dependent on the striking effect, resulting in kernel damage. The tooth plate component was; mainly in contact with the maize ears in a planar structure, had a strong striking effect and large area; and the threshed maize grain was quickly separated under the action of the tooth plate. The threshing effects of the two components were similar. 

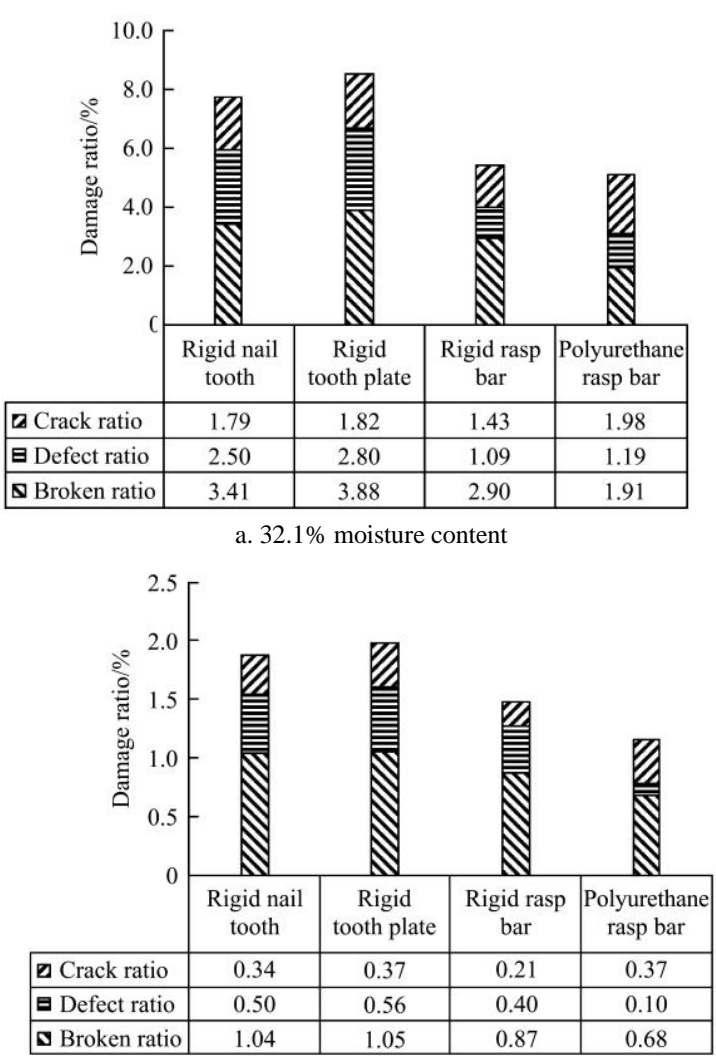

b. $25.6 \%$ moisture content

Figure 9 Statistical results of maize grain damage

\section{Conclusions}

1) A maize grain threshing test-bed combined with the maize combine harvesting machine was able to be developed. The threshing and separating process of maize grains were recorded and analyzed using a high-speed camera. The influence of different threshing components on the threshing efficiency of maize grains was studied. The threshing process and damage caused by the high moisture content of maize grain were elucidated. This provided a reference for designing and optimizing the threshing and separating device of the combine harvesting machinery for maize grain.

2) It was observed that different types of threshing components have different modes of action in the threshing process, resulting in various threshing and separating effects. The threshing and separating effects of the perforated concave plate were obviously lower than that of the round steel concave plate. The threshing effect of the nail tooth and the tooth plate were similar to one another; much like the threshing effect of the rigid rasp bar and polyurethane rasp bar.

3) It is known that when the maize grains' moisture content level is high, different types of threshing components have obvious influence on the kernel damage rate. Combined with threshing process, the analysis of maize grain damage under various conditions highlights the significant impact of moisture content on the damage rate and level of damage in maize grains.

\section{Acknowledgements}

The authors acknowledge that this research was financially supported by the National Natural Science Foundation of China (Grant No. 51975256, 51605196); China Postdoctoral Science Foundation (2016M591788); Jiangsu Key Research and Development Program of China (BE2016356).
The authors also acknowledge all the postgraduate students who provided their input to this study, and greatly appreciate the anonymous reviewers for their constructive comments that improved this manuscript.

\section{[References]}

[1] Ministry of Agriculture and Rural Affairs of the People's Republic of China Significant progress has been made in the mechanization of major crops Available at: http://www.moa.gov.cn/ztzl/ncgzhy2017/pandian/201712/ t20171219_6105958.htm. Accessed on [2017-12-05]

[2] Yang L, Cui T, Qu Z, Li K H, Yin X W, Han D D, et al. Development and application of mechanized maize harvesters. Int J Agric \& Biol Eng, 2016; 9(3): 15-28.

[3] Geng A J, Yang J N, Zhang Z L, Zhang J, Zhang R S. Discuss about the current situation and future of maize harvest machinery about domestic and abroad. Journal of Agricultural Mechanization Research, 2016; 38(4): 251-257. (in Chinese)

[4] Chen Z, Hao F P, Wang F D, Su W F, Cui J W. Development of technology and equipment of maize harvester in China. Transactions of the CSAM, 2012; 43(12): 44-49. (in Chinese)

[5] Li X P, Xiong S, Geng L X, Ji J T. Influence of water content on antipressing properties of maize ear. Transactions of the CSAE, 2018; 34(2): 25-31. (in Chinese)

[6] Qu H J, Zhang D L, Yang T W, Xu Z D. Experimental research on maize threshing performance affected by moisture content. Journal of Agricultural Mechanization Research, 2014; 36(2): 153-156. (in Chinese)

[7] Li S K, Wang K R, Xie R Z, Li L L, Ming B, Hou P, et al. Grain breakage rate of maize by mechanical harvesting in China. Crops, 2017; 2017(2): 76-80. (in Chinese)

[8] Yi K C, Zhu D W, Zhang X W, Yao Z H, Liu Z. Effect of moisture content on maize grain harvesting mechanization. Journal of Chinese Agricultural Mechanization, 2016; 37(11): 78-80. (in Chinese)

[9] Liu J Y, Cui Z K, Ma J C, Jiao W. Problems and countermeasures of wheat maize rotation production mechanization for main crops in Huanghuaihai Region. Journal of Agricultural Mechanization Research, 2016; 38(5): 259-263. (in Chinese)

[10] Gao L X, Li F, Zhang X W, Zhang Y L, Liu X, Jiao W P. Mechanism of moisture content affect on maize seed threshing. Transactions of the CSAM, 2011; 42(12): 92-96. (in Chinese)

[11] Chowdhury M H, Buchele W F. The nature of maize kernel damage inflicted in the shelling crescent of grain combines. Transactions of the ASABE, 1978; 21(4): 610-614.

[12] Kustermann M, von Maiskoerner S B. Impact load on maize grains. Grundlagen Landtechnik, 1987; 37(4): 121-131.

[13] Petkevichius S, Shpokas L, Kutzbach H D. Investigation of the maize ear threshing process. Biosystems Engineering, 2008; 99(4): 532-539.

[14] Li X P, Ma F L, Gao L X. High-speed photograph analysis on threshing process of maize seed. Transactions of the CSAM, 2009; 40(11): 46-49. (in Chinese)

[15] Zhang X W, Yi K C, Gao L X. Contacting mechanics analysis during impact process between maize seeds and threshing component. Chinese Agricultural Science Bulletin, 2015; 31(14): 285-290. (in Chinese)

[16] Fu H, Lü Y, Li Y S, Yu J Q. Analysis for maize threshing process based DEM. Journal of Jilin University (Science Edition), 2012; 42(4): 997-1002. (in Chinese)

[17] $\mathrm{Yu} \mathrm{Y.} \mathrm{Research} \mathrm{on} \mathrm{analysis} \mathrm{method} \mathrm{of} \mathrm{maize} \mathrm{threshing} \mathrm{based} \mathrm{on} \mathrm{3D}$ DEM. Doctoral dissertation, Changchun: Jilin University, 2013; 134p. (in Chinese)

[18] Xu L, Ma J, Wang Z, Yang Y, Chen L, Fang L. Design and experimental study on stripping device of maize harvester. International Agricultural Engineering Journal, 2018; 27(3): 210-221.

[19] Di Z F, Cui Z K, Zhang H, Zhou J, Zhang M Y, Bu L X. Design and experiment of rasp bar and nail tooth combined axial flow maize threshing cylinder. Transactions of the CSAE, 2018; 34(1): 28-34. (in Chinese)

[20] Cui Z K, Di Z F, Zhou J, Zhang H, Bu L X, Gao Q. Design and research on 5TYS280 maize threshing and cleaning test bench. Journal of Agricultural Mechanization Research, 2017; 39(5): 113-117. (in Chinese)

[21] Yang L Q, Wang W Z, Zhang H M, Li L H, Wang M M, Hou M T. Improved design and bench test based on tangential flow-transverse axial flow maize threshing system. Transactions of the CSAE, 2018; 34(1): 35-43. (in Chinese) 